\title{
Educação popular ainda é necessária? Contribuições do Paidéia para a emancipação das juventudes na cidade
}

\author{
La educación popular aún es necesaria? Contribuciones del Paidéia para \\ la emancipación de la juventud en la ciudad
Is popular education still needed? Contributions of the Paidéia for emancipation of the youth in the city

\section{Samuel Crissandro Tavares Ferreira ${ }^{1}$}

\begin{abstract}
Resumo
O trabalho aqui sistematizado compreende parte da dissertação da pesquisa E Se a Cidade Fosse Nossa: A Educação Popular Contribui na Emancipação das Juventudes na Cidade?, que a nível de mestrado investigou as contribuições do curso Paidéia, projeto que trabalha pelo viés da Educação Popular, para os jovens da cidade do Rio Grande. Com intuito de aprofundar o debate da emancipação, foi utilizado a perspectiva teórica marxista da emancipação humana, para analisar de a relação entre as categorias Educação Popular, Juventudes e Cidade. Como base metodológica para o desenvolvimento desta pesquisa foi utilizado os indicadores emancipatórios.
\end{abstract}

Palavras-Chave: Educação Popular; Juventudes; Cidade; Emancipação; Paidéia.

\section{Resumen}

PEl trabajo aquí sistematizado comprende parte de la disertación de la investigación E Si la Ciudad Fosse Nuestra: La Educación Popular Contribuye en la Emancipación de las Juventudes en la Ciudad ?, que a nivel de maestría investigó las contribuciones del curso Paidéia, proyecto que trabaja por el sesgo de la Educación Popular, para los jóvenes de la ciudad de Rio Grande. Con el fin de profundizar el debate de la emancipación, se utilizó la perspectiva teórica marxista de la emancipación humana, para analizar la relación entre las categorías Educación Popular, Juventudes y Ciudad. Como base metodológica para el desarrollo de esta investigación se utilizaron los indicadores emancipatorios.or.

Palabras claves: Educación Popular; Jóvenes; Ciudad; Emancipación; Paideia.

\begin{abstract}
The work here systematized includes part of the dissertation of the research And if the City Fosse Nossa: Popular Education Contribute to the Emancipation of the Youth in the City ?, that at the master's level investigated the contributions of the course Paidéia, project that works for the bias of Popular Education, for the youth of the city of Rio Grande. In order to deepen the emancipation debate, the Marxist theoretical perspective of human emancipation was used to analyze the relationship between the categories Popular Education, Youth and City. As a methodological basis for the development of this research, the emancipatory indicators were used.
\end{abstract}

Keywords: Popular Education; Youths; City; Emancipation; Paidéia

\footnotetext{
${ }^{1}$ Mestre em Educação; Universidade Federal do Rio Grande (FURG); Rio Grande, Rio Grande do Sul, Brasil; Email: samukacrissandro@gmail.com
} 


\section{Introdução}

O Sul da educação popular é a construção de uma educação com uma "veia" política crítica, e que possa a partir dos sujeitos que a constroem e participam, problematizar o mundo, na corporificação das palavras, no pronunciamento das palavras, na humanização e no entendimento de que é necessário resistir com base em um pensamento que por mais que seja ácido e que gere mal-estar ao pensamento dominante, seja contundente no que almeja transformar.

Uma das preocupações e problematizações deste trabalho ${ }^{2}$ é a curiosidade epistemológica que eu tinha para saber se o Paidéia conseguia ser mais que um curso preparatório para o Enem, e se mesmo possibilitando uma entrada e ingresso ao nível superior e técnico de educação, ele auxiliava na emancipação, ou de certa forma, apontava para a mesma.

Entendo que a centralidade da educação popular, que é a construção de alternativas (pois a E.P. tem suas particularidades em cada lugar, contexto e etc.), possibilidades de transformação, projetos que desafiem a realidade para que chegue em um outro estágio da práxis, e por isso, a emancipação (e também a humanização, que aqui se encaixam e são sinônimas) não deve ser um mero discurso.

Dito isso, como emancipação em Marx e humanização em Freire, possuindo força conceitual e teórico-prática próximas, ao analisar as entrevistas, compreendi alguns elementos elencados por esses sujeitos como categorias que me levaram a desvendar a conexão entre o Paidéia (E.P.), os ex-educandos/educandas sujeitos da pesquisa (jovens e com entendimento acerca das juventudes) e Rio Grande (Cidade). Certamente que a perspectiva de educação trago aqui, se coloca como um processo dialético e dialógico, que deve transformar e também ser transformado. Em miúdos, com base no conhecimento dos sujeitos que participam da educação popular, construir esse viés crítico. Por isso, alguns elementos sublinhados aqui nessa etapa, denotam aspectos que eram trabalhados dentro desse espaço de educação popular que é o Paidéia, muito importantes, que indicam para emancipação ou para intenções emancipatórias.

\footnotetext{
${ }^{2} \mathrm{O}$ presente artigo é parte de minha pesquisa a nível de mestrado que realizei pelo PPGEDU-FURG. O título da dissertação é E Se a Cidade Fosse Nossa: a Educação Popular Contribui na Emancipação das Juventudes na Cidade? (FERREIRA, 2018). Disponível em:https://sistemas.furg.br/sistemas/sab/arquivos/bdtd/0000012524.pdf
} 


\section{Desenvolvimento da pesquisa}

Dentro do roteiro de perguntas da entrevista/diálogo, um dos questionamentos centrais foi como o Paidéia contribuiu (isso se contribuiu!) para a criticidade, para o aprendizado e em outros aspectos pessoais. $\mathrm{Na}$ entrevista/diálogo, muitos aspectos apareceram. Começo aqui com esse trecho da fala do Rafa:

Cara não é nem questão que contribuiu para a minha visão política, mas é que eu acho que é um lugar onde eu tive espaço para mostrar a minha visão entendeu? Eles me deram espaço para mostrar minha visão e estavam abertos a ter a visão do jovem e trocar ideias tá ligado? Não sei se, se o intuito era isso do curso, mas tipo, cara acho que foi um dos primeiros lugares que eu pude falar tá ligado? Eu sempre tive na escola e na escola sempre se fala que o que o professor fala é o certo tá ligado? $\mathrm{O}$ aluno tem que baixar a orelha escutar e ... levar aquilo ali como certo pra vida tá ligado? E lá no Paidéia não, eles estavam abertos a ouvir nossas dúvidas, a ouvir nossos questionamentos, a ouvir a nossa argumentação, e acho que essa visão me ajudou a formar tá ligado? Não que eu não tivesse essa visão, mas me ajudou a debater ... (Rafa)

Entendo que, nesse caso, o sujeito afirma na entrevista que sempre que colocava o seu ponto de vista em alguma discussão, "troca de ideia" ou debate, percebia que por vezes aquele ponto de vista não tinha valia, ou se houvesse contrariedade, por vezes ficava por isso mesmo. Do mesmo modo, a sua identidade não era aceita na escola, na própria casa e na família (no caso do Rafa, o fato de gostar de coreografias, danças, e deixar esse aspecto de sua identidade de lado pela não aceitação), e no caso do Paidéia, já havia uma diferença pelo curso entender que as diversas identidades, as múltiplas culturas e a diversidade se fazer presente, havia uma grande chance de submeter os sujeitos em um ambiente com visões de mundo amplas.

O sujeito afirma que já havia a prática de debater e tinha pensamentos e argumentos políticos, mas na naquela diversidade e na própria acolhida dos educadores, essa prática se intensificou. Analisando essa questão e outras que foram levantadas pelo sujeito (e a dos outros sujeitos, mas que se aproximam com essa), compreendo uma profunda contribuição do Paidéia para com o desenvolvimento do pronunciamento da palavra, da capacidade de os sujeitos entenderem o mundo de certo modo e socializar essa visão, com entendimento de que sua perspectiva, se for refutada, visará uma argumentação, e daí um outro aprendizado ou uma radicalização daquilo que já entendia. E por isso prossegue:

Cara como pessoa acho que contribuiu muito porque eu tinha muito de julgar as pessoas tá ligado, querendo ou não tipo, agente que, não sei se todo negro, mas agente que sofre preconceito acaba criando um preconceito, tipo assim, tem um grupo ali diferente de mim e eu não vou me misturar porque vão me olhar diferente, e quando eu cheguei no PAIETS e vi assim uma diversidade gigantesca tá ligado? 
Várias pessoas de várias etnias, vários jeitos, tinha ...pessoas com vivências diferentes de mundo, orientações sexuais tá ligado? E até diferentes, tipo, religiões, ou diferentes tipos de formação familiar ... (Rafa)

A possibilidade de imersão em um ambiente prolífico de identidades encurtou a distância entre os sujeitos. Poderia ter acontecido ao contrário, e a partir da intensificação de algum conflito, gerar alguma consequência desagradável. Cabe informar que desde o momento da seleção para o Paidéia, nós ressaltamos que a educação popular possui um acúmulo político-pedagógico, preparando já os futuros e futuras educandas acerca da construção de um espaço no mínimo democrático, aonde a possibilidade do "outro", diferente de si mesmo, poderia estar ao seu lado, e mesmo sendo diferente, o processo de socialização e interação seria necessário.

Do mesmo jeito, alertamos que não "respeitamos o desrespeito", e opiniões homofóbicas, machistas, racistas e outras fundamentalistas e reacionárias, não eram somente uma opinião, mas, sim, atividades e manifestações criminosas, que num contexto geral, perante um estado de direito e de um contexto de direitos humanos, tais atividades e manifestações criminosas seriam a quebra total de um paradigma acertado coletivamente de respeito e tolerância.

Com isso, se cria o início de um espaço de humanização, aonde entender o outro como igual e semelhante é eficaz na luta pelo "encurtar da distância" social. Nesses trechos que o Rafa aponta esses aspectos entendo que está um dos compromissos da educação popular (e de qualquer educação, a princípio), que é a análise, a leitura crítica do mundo. A reflexão e a mínima noção de se estar em mundo desigual, e que a partir disso, nos incutem a divisão, o afastamento um dos outros, na construção de preconceitos, racismos e violências entre nós mesmos, e a partir disso, o ódio é concretizado, pois nos vemos como menos e outros, menos ainda.

Para isso, a educação popular no faz entender que mesmo na diferença, somos do mesmo planeta, sentimos dor, e sofremos muito com o processo de dominação, e por isso, precisamos ler a realidade e o que essa realidade está nos impondo, compreendendo então que nós latino-americanos, somos culturalmente diferentes, e isso não é uma indigência, mas sim uma riqueza:

Desde los albores de ella em Simón Rodríguez, quien dijo que debíamos construir uma educación que nos hiciera americanos y no europeus, pasando por Elizardo Pérez, quien propuso que la educación debe ser organizada com ele proyecto político-económico- social- cultural de realidade que se tiene, y Paulo Freire - quien nos enseño que el ejercicio básico de su propuesta metodológica era aprender a leer 
la realidad - la educación popular há ido consituyndo uma propuesta donde los territórios, lo local, hacen que el ejercicio educativo siempre sea contextualizado. (MEJÍA, 2013, p.372)

Mejía nos salienta a construção de aspectos de leitura e de percepção de mundo, da realidade, concentrado e acumulados em Freire, mas já articulados desde o século XIX. Certo que os pensadores e pensadoras da América Latina, educados pela Europa, mas querendo romper com as mesmas, encontraram desafios grandiosos nesse processo emancipatório. Com isso, junto dessa afirmação desse educador e pesquisador colombiano, resgato a importância do Paidéia como educação popular de permitir um espaço-tempo capaz de potencializar a indignação, a rebeldia, a criticidade, a humanização, a solidariedade e a emancipação, com base em nossa realidade. A importância de considerar e reconsiderar as experiências das pessoas que lá estavam inseridas, participando, estudando, por mais que essa experiência fosse bem diferente da tua:

Eu acho que aquela concepção de que o mundo não gira ao meu redor, de que existem realidades diferentes da minha, e que existem pessoas diferentes e isso é por causa da vivência delas e não necessariamente porque alguma coisa foi implantada na cabeça dela, mas sim porque, o mundo em que elas vivem é diferente do meu, ou até mesmo pessoas que tem até o mesmo mundo meu, só que a vivência não é parecida. (Anne)

A contribuição está presente nessa percepção mais ampla da realidade, de leitura de mundo, leitura da realidade e entendimento e acolhimento do outro para além das particularidades ou para aqueles aspectos que não convergem em direção aos teus. Essa afirmação da Anne é muito importante, pois o espaço do Paidéia permitiu que ele conseguisse a visualizar não somente essas diferenças, mas como ela mesmo disse, permitiu identificar-se como feminista entendo a luta das mulheres, permitiu que entendesse um pouco mais sobre o desprezo e a subalternização que ocorre em nossa sociedade para com a comunidade LGBT, e permitiu com que entendesse que na sua vida ela poderia enfrentar a realidade (por mais que ela afirmasse que "não fazia muita coisa", "não saia muito de casa"), mesmo em meio as adversidades:

(...) eu entrei na universidade em fevereiro, pelas leis de cotas, de afrodescendentes e de indígenas e pardos no caso. Eu fui entrevistada pela comissão, da FURG, e eles interpretaram, que eu, primeiramente, que no edital deles dizia que quem se autodeclarasse preto, não tinha necessidade de levar a certidão do pais nem a de si próprio comprovando que tinha a cor. Eu me auto declarei preta e não parda, cheguei na entrevista e me perguntaram se eu me autodeclarava parda, e disse que eu me autodeclarei preta e não parda. E as pessoas, tudo bem, então e me indeferiram. Fiz o meu recurso, levei para o protocolo da FURG, no dia certo assinado ali pelo pessoal do protocolo, e mesmo assim continuei sendo indeferida, aí passou a segunda semana da FURG e eu já tava com a minha matrícula trancada, 
tive que aí ser assistida pela defensoria, contei todo esse meu caso, peguei tudo que tinha de documentos, e tudo mais, ainda mais, além disso, o meu processo na FURG estava em andamento, e ele ficou durante 1 mês e meio em andamento(...) (Anne)

A luta pelo direito ao direito, por algo que já está garantido, por vezes se faz por muita resistência, mas principalmente entendendo que as conquistas não estão dadas, mas que é preciso lutar, por mais que a universidade, no caso a FURG, trabalhe com uma afirmação de que é compromissada com a emancipação social e possui uma responsabilidade com a comunidade:

\begin{abstract}
Muito porque foi uma omissão da FURG, e essa parte assim do meu recurso, eu não sei se eles não leram, eu nunca vou saber, porque o próprio, tu pode até abrir pra ler lá no... na FURG, no SISU FURG, a própria comissão, ela nunca falou em nenhum momento, de todos os participantes, porque do indeferimento, eles não falaram nem na entrevista, nem tampouco do recurso, então eu nunca vou saber o porquê que eu fui indeferida, na entrevista, nem tampouco ... e isso é o princípio da publicidade, que tá isso na constituição (...)E aí o que acontece? No processo da decisão do juiz, eles alegam que fizeram uma nova entrevista comigo, e mesmo assim eu não cumpri os requisitos, isso, não aconteceu. Eles mentiram! E o que acontece. Juiz, tudo bem aconteceu isso, assinou, deu. E a defensora continuou ... a não, não quero mais continuar nisso, eu aceito, eu achei interessante até. E eu não, eu vou recorrer. E até hoje eu não sei o que tá acontecendo né, não sei nem seu eu perdi o processo, se eu perdi o tempo do processo se eu vou ser assistida por outras pessoas, eu não sei, não sei mais o que está acontecendo mesmo, não sei se foi causa perdida, causa ganha ... até agora sem resposta. (Anne)
\end{abstract}

Esse é mais um capítulo na vida de um sujeito, de uma mulher, jovem, negra, filha de trabalhadores, oriunda das camadas populares e que faz da sua vida um desafio, uma interrogação para essa sociedade que se diz democrática, mas que por vezes é pura "sloganização" e engodo. Com base nisso, entendo, e a própria Anne vem afirmar isso, que é necessário entender essas limitações e do mesmo modo resistir:

Acho que sim, acho que o Paidéia me ensinou a resistir porque nossa, passou muito. Passou quanto tempo? Só 7 meses essa questão do processo. 7 meses resistindo, eu nunca imaginei que ia ser tão devagar isso... (Anne)

O Paidéia, com todas as suas limitações, permitiu o entendimento de que a realidade não se constitui de determinismos, mas pelo contrário, os condicionamentos são por vezes violentos e duros, mas é possível romper com eles.

Essa afirmação da Anne, dizendo que o Paidéia ensinou-a resistir, veio de encontro na análise, na busca pelo entendimento de que se o Paidéia contribuísse como educação popular na emancipação das juventudes na cidade, como ele contribuía? 
Certamente que para cada sujeito e para cada contexto, a construção de sua emancipação ou de sua intenção de emancipação é diversa, mas entender que o próprio curso conseguiu auxiliar na transformação de algo ou na transformação de que se é possível lutar pela transformação, já é extremamente válido. Não queremos e não buscamos como educação popular a média, mas queremos aprofundar o trabalho nessa perspectiva e por isso, é necessário entender alguns aspectos centrais no contexto do Paidéia. Do mesmo modo, entendemos que a partir de Freire, que por mais que os sujeitos de modo individual encabeçam suas lutas e tentativas de não serem mais subordinados ou dominados, há também a necessidade dentro de um processo de humanização, que as lutas se deem em coletivo, no compartilhar das dificuldades entre estas pessoas oprimidas, e aqui nesse caso, entre estes jovens:

Esta busca do ser mais, porém, não pode realizar-se no isolamento, no individualismo, mas na comunhão, na solidariedade dos existires, daí que seja impossível dar-se nas relações antagônicas entre opressores e oprimidos. (FREIRE, 2016, p.129).

E essa afirmação se acopla com o que Santos (2011) destaca sobre a lógica de uma cidadania atrofiada e de um não-cidadão do terceiro mundo:

\begin{abstract}
Mas há cidadania e cidadania. Nos países subdesenvolvidos, de um modo geral, há cidadãos de classes diversas; há os que são mais cidadãos, os que são menos cidadãos e os que nem mesmo ainda o são.(...)Em nenhum outro país foram assim contemporâneos e concomitantes processos como a desruralização, as migrações brutais desenraizadoras, a urbanização galopante e concentradora, a expansão do consumo de massa, o crescimento econômico delirante, a concentração da mídia escrita, falada e televisionada, a degradação das escolas, a instalação de um regime repressivo com a supressão dos direitos elementares dos indivíduos, a substituição rápida e brutal, o triunfo, ainda que superficial, de uma filosofia de vida que privilegia os meios materiais e se despreocupa com os aspectos finalistas da existência e entroniza o egoísmo como lei superior, porque é o instrumento da busca da ascensão social. Em lugar do cidadão formou-se um consumidor, que aceita ser chamado de usuário. (SANTOS, 2011, p. 87-88).
\end{abstract}

Dito isso, se faz mais do que necessário a construção da educação popular na perspectiva de nos perceber inconclusos, condicionados, e não determinados, encontrando explicações mitológicas para justificar as imposições que recebemos na ordem do dia. $\mathrm{Na}$ solidariedade dos existires, como escreveu Freire, há uma grande possibilidade de se romper com essa cidadania atrofiada (ou não-cidadania), que gerou o consumidor, o usuário, como ressaltou Santos. 
Tenho certeza que dentro de um processo de transformação individual e também coletiva, a entrada na universidade é extremamente importante, por mais que ela esteja também dentro de uma lógica capitalista, e gere uma grande exclusão. De igual modo, a universidade na contemporaneidade, se torna imprescindível para as classes populares, e daí se torna importante a disputa contra hegemônica no/por esse espaço, que por muito tempo vem se configurando como espaço que se legitima o pensamento, a ciência, a cultura, mas que se tornou elitista e monocultor.

\section{Do que as camadas populares precisam? Aprofundando o debate da educação popular e da educação democrática}

Entramos então na questão de que do mesmo modo que é importante para o povo entrar na universidade, é necessário que a universidade receba as camadas populares e entenda e aprenda com esses sujeitos, uma perspectiva diferente de viver e sobreviver. Nesse contexto o Paidéia se torna um grande projeto que permite a entrada de sujeitos na universidade, porém a análise aqui se deu e tem se dado para além disso, tentando entender que somente entrar na universidade não denota emancipação social. É importante, mas não é sinônimo (o caso da Anne é um exemplo!).

Para que se tenha um grande aproveitamento da vida de estudante ou pesquisador, os sujeitos das camadas populares, mulheres e homens, jovens, precisam muito mais do que somente uma matrícula que permita entrar e sair da universidade. Precisa-se de moradia, de alimentação, bolsas, de cotas, benefícios e auxílios garantam as condições necessárias certas para que uma educação de qualidade se configure.

Grande parte dos estudantes da universidade consegue o ingresso, muitas vezes passam pelo processo de cursos da educação popular, mas não conseguem se manter na universidade. As dificuldades são grandes, as mazelas são diversas e complexas, e por isso, esses sujeitos optam e historicamente optaram pela garantia de um emprego ou subemprego que garantisse a sua subsistência.

Porém se fez necessário entender se o Paidéia também possibilitou essa entrada na universidade, se a contribuição para a realização da seleção foi produtiva/positiva. Pablo nos fala sobre isso e da necessidade de se ter cursos de educação popular que auxiliem as pessoas:

Não, pelo contrário velho, pelo contrário. Eu tentei fazer o Máxximus, que era perto da minha casa, não consegui, tá ligado? Consegui a vaga ali no Paidéia e ele foi um divisor de águas, uma coisa é certa, quem dera que a gente pudesse ter um núcleo de Paidéia aqui no hospital, lá no Silva Paes, no Cedro, no Marinha tem, no Cassino tem, pudesse inserir isso aí lá na Quinta, tá ligado, pudesse ter no Caic, outro ponto 
estratégico também, quem dera! Nos pudesse fortalecer isso aí, ter recurso, conseguir recurso, para aumentar o leque de professores, entendesse? A gente vai conseguir alcançar, quem realmente precisa, tá ligado? Porque todo mundo que faz precisa, não que não precise, eu fui correr atrás porque não tinha condições de pagar um pré-vestibular, tá ligado? Um cara que trabalha que já tem uma vida aí já, e quer correr atrás de mais alguma coisa, vou ser sincero isso aí é fundamental, sem isso aí eu não teria entrado para Geografia no ano passado, é que eu não consegui fazer a minha matrícula, eu vi as listas erradas, eu me desatentei, foi falha minha, mas sem o Paidéia eu não tinha passado, tá ligado? (Pablo)

Com isso destaca-se como que para esse sujeito o projeto se tornou significativo para que alcançasse seu objetivo ao conseguir a sua vaga na universidade. Por infelicidade, perdeu a matrícula, mas percebeu que era possível alcançar os seus objetivos a partir do Paidéia, que fez com que desenvolvesse as suas capacidades.

Ou aspecto que se destaca, é importância que o Paidéia e outros concentram ao se disponibilizar a auxiliar esses sujeitos em suas lutas pelo direito a estudar, pelo direito ao ensino técnico e superior, do mesmo modo que se destaca para o Pablo, a importância do curso para ele e para as outras pessoas, onde as mesmas despendiam um grande esforço para não perder o foco, e conseguir entrar na universidade:

Quantas vezes de bikezinha eu vinha... não vai longe cara, pra tu ver o quanto é necessário o cara jogar isso aí para tudo quanto é bairro, pra aumentar os núcleos, que tu vê a real necessidade das pessoas, tá ligado, porque tinha pessoas ali, porque eu sou cara que me atento muito a detalhes, não é questão de tá olhando "ah o sapato da pessoas!", tu olha a conjuntura inteira, eu sentava no fundo de uma sala de aula, e a gente tinha gente de tudo quanto é bairro ali, então bem ou mal, nós tinha pessoas que de repente tinha condições de pagar um curso, saca ? Mas nós tínhamos gente que não tinha condições de pagar um curso, que ia pra lá com fome, tá ligado? Mesmo jeito que tinha aquela menina lá que ia pra lá e que sentava toda encabulada, que ela tava sentada que ela tava usando uma botina de trampo, saca? Tu vai vendo a conjuntura do bagulho, tu vê que é um é negócio necessário tá ligado? Que as pinta tavam saindo lá da Vila Maria mano, pra vir fazer aula aqui, tá ligado? É foda, porque as vezes a pessoa deixa de comer um bagulho, ou de comprar 7 pães, para comprar 3 pães pra sobrar dinheiro, pra pegar o ônibus pra vir pra cá... pra assistir aula, saca? (Pablo)

É importante destacar a força e a luta que os sujeitos que estavam no Paidéia faziam para estar no curso, para participar, para contribuir um pouco mais e para entender um pouco mais com as aulas, com o aulões e com outras atividades. Ainda nessa linha, segue o cotidiano de se tentar fazer com que a educação popular, que já está efetivada, se aprofunde e se alastre:

Então é extremamente necessário que isso seja... já é concretizado, já é concreto tá ligado? A questão é, lutar para que? Pra que se radicalize mais, pra gente ter mais radicais, que possam vim à tocar, pra gente aumentar ... mais células, são mais átomos, é mais agitação, é mais força que vai ter. (Pablo) 
No atual contexto socioeconômico e político, é indispensável projetos que pensem na transformação de uma sociedade. Radicalizar a educação é um caminho promissor quando se pensa em romper com as contradições de uma sociedade que é extremamente desigual em todos as esferas possíveis. A educação transformadora, transforma pessoas, e essas, se engajam contra qualquer projeto violento de sociedade, principalmente o capitalismo. $\mathrm{O}$ Paidéia então se torna fundamental em sua práxis, em seu projeto de educação popular:

Dá uma potencializada, já dá uma potencializada, e é o que o Paidéia oferece cara, ele é um potencializador, tu tem lá o tem potencial,tu sabe, ele tá lá guardadinho lá dentro da... só que tu não consegue chegar lá, tá ligado, então se o cara... a cada dia que vem tu vai assistindo uma aula ou outra e tu vai vendo, bá é possível ! Eu posso ir um pouco mais além, eu posso ir um pouco mais longe, tá ligado? (Pablo)

Paramos em nossas limitações ou tentearemos seguir um pouco mais? Será que conseguiremos romper com as nossas situações-limite? A educação popular contribui com isso? Essas perguntas suleadoras é que me fizeram nas entrelinhas, investigar o processo no qual eu também estava inserido. Através de hipóteses entendia algumas relações, mas não conseguia entender algumas outras, essas outras somente agora percebo. Dentre elas, como se fez importante construir certas atividades que acabavam se tornando trabalhosas, mas que ao mesmo tempo, foram extremamente indispensáveis a relação ensino-aprendizagem, na comunicação constante de que é possível ir além, mas sem esperanças ingênuas.

A educação popular em sua história na América Latina, consiste em acumulados diversos, com base em suas territorialidades, porém, o ponto de unidade é o compromisso com as populações oprimidas e de igual modo, a projeção de uma transformação real:

Ao percorrer a tradição latino-americana da educação popular, vamos identificar, tanto nas formulações efetuadas em períodos mais remotos da sua história no continente (século XVIII à primeira metade do século XX), quanto nas experiências mais recentes (as iniciadas na segunda metade do século XX), as ideias e, ao mesmo tempo, expectativas de "movimento", "criação cultural" e "transformação social". (JARA; FALKEMBACH, 2013, p.151).

Em sua concepção de transformação de mundo, a educação popular se acopla com ideais e práticas de movimentos sociais e políticos, pois os mesmos estão configurados com a responsabilidade de não somente pensar sobre o mundo, mas revolucioná-lo, possibilitando uma vida mais justa, democrática e emancipada.

Pensar essas contribuições, tanto na perspectiva de auxílio ao ingresso na universidade, quanto na contribuição emancipatória, na concepção de entender-se com a gente 
transformador da realidade, é indispensável nessa organização das contribuições da educação popular que reforça a contundência da mesma. Como segue dizendo a Carol:

Não, contribuiu com a minha criticidade, bastante assim, eu já tinha uma visão bem crítica das coisas e contribuiu bastante, contribuiu para eu ler coisas da teoria marxista, contribuiu com a minha visão política, contribuiu com a minha escolha de curso que eu queria fazer, o que mais deixa eu pensar no que contribuiu, é foram essas coisas assim, superficialmente foi isso. (Carol)

Assim, mesmo esse sujeito sendo extremamente crítico, com uma sensibilidade desenvolvida, afirma que o Paidéia teve seu papel importantíssimo para si. Do mesmo modo que o curso vinha reforço e dando algumas direções. O desenvolvimento de uma educação que possibilitasse o protagonismo, e que fincasse a ideia de que a busca, a pesquisa e a investigação é fundamental em qualquer projeto de educação, e principalmente de autonomia:

Eu vi isso que as aulas eram um modo de eu abrir minha mente, de eu chegar contribuir entende, não só eu chegar e esperar que eles me ensinassem tudo, mas que eu chegasse em casa e pesquisasse, chegasse em casa e estudasse, eu vi isso bastante dos professores lá, o pessoal bem, não tava nessa educação bancária, de depositar o conteúdo nos alunos, tava bem assim educandos e educadores, educadores e educandos ... (Carol)

Para algumas pessoas, essa busca por autonomia era algo bem impactante, e muitos não sabiam lidar com tal autonomia, que esperava do educador ou da educadora todo um esquema para se "decorar" os conteúdos. Outras aproveitaram essa perspectiva para buscar a sua autonomia e desenvolvê-la:

\begin{abstract}
Contribuiu com isso que eu te falei já, que me instigou a fazer pesquisas sobre outras filosofias, fiz amigos também lá, que foram também importantes assim que se identificavam comigo e acredito que essa identificação que o curso me trouxe é uma coisa que me disse assim, ah tu não está sozinha no mundo. Tem outras pessoas que pensam que nem tu . Isso é bem importante! Isso foi uma coisa que eu vi no curso, dos professores também. De ti, da Ju. Assim, a gente pensa que... as vezes a gente tem umas ideias de mundo assim que a gente tá num lugar assim... que que eu tô fazendo aqui? Eu sou um estranho aqui, um alienígena, ninguém pensa igual a mim, mas aí tu vai conhecendo alguma pessoas que são assim também, que também tem essa concepção e tu não te sente tão sozinho, tu sente que as coisas podem mudar entendesse? E que tu sendo a mudança, mesmo que tu seja só um, tu já faz a diferença, isso eu vejo porque tu não é só 1 , tem outros " 1 " que nem tu entende? E isso eu vi no curso bastante ... uma concepção (acredito que ela quis dizer constatação) que eu posso te dizer. (Carol)
\end{abstract}

Para além dessa contribuição no desenvolvimento intelectual, das potencialidades que ocorrem, a socialização que ocorre e a identificação entre pessoas diferentes que querem transformar a si próprios e ao mundo em que vivem, é uma contribuição extremamente 
importante para esses jovens da cidade. Por isso, entendo com base nas principais categorias que foram aparecendo no processo de análise, que há uma contribuição nesse contexto do Paidéia, o que legitima esse projeto na busca por uma metodologia político-pedagógica que compreenda esses sujeitos e as suas limitações e condicionantes.

A partir dessas constatações que foram evidenciadas, podemos não somente perceber as principais contribuições para as juventudes, mas também, entender de igual modo, algumas possibilidades de se aprofundar, de buscar as raízes da educação popular e ser radical nesse projeto de romper com as situações limite que estão colocadas como naturais ou impossíveis de serem derrubadas, confeccionando os inéditos viáveis.

Certamente que o processo é um caminho que temos que percorrer, as tentativas de se tentar possibilitar maiores transformações não somente nas atividades de aula, mas também nas atividades de formação para as educadoras e educadores, foram sempre válidas, pois o ímpeto foi sempre de prosseguirmos com um projeto, que mesmo sendo refletido, e artesanalmente feito no coletivo, ele não nos pertence.

Muitas coisas acontecem entre a semeadura e a colheita, e esse processo trabalhoso não deixa dúvidas sobre seu cansaço, mas por outro lado, não titubeamos ao perceber que esse processo é sempre válido, porque de algum modo, a partir do momento que nos lançamos a resolver os problemas de nossa sociedade, estamos transformando a nós mesmos, assim como o ato de ensinar, que primeiramente nos dá uma sensação de impossibilidade de ser o comunicador de determinadas questões, mas ao nos fazermos responsáveis por determinado conhecimento e também responsáveis para compartilhar, entendemos que quem sai ganhando somos nós. Nesse diálogo constante e nessa perspectiva dialética que se faz uma educação popular com contribuições diversas.

\section{4. "Pontos de encontro" versus "pontos turísticos": rupturas e interrupções necessárias no cotidiano da cidade.}

I wanna heal, I wanna feel Like I'm close to something real I wanna find something I've wanted all along

Somewhere I belong

(Linkin Park)

Um bom lugar Se constrói com humildade, é bom lembrar...

(Sabotage) 
Quanto a construção de identidades e resistência na cidade, entendemos que ela é diversa, principalmente porque diversa são as juventudes e também as condições com que as mesmas vivem e sobrevivem. A cidade como locus, como espaço de atuação e intervenção, não está dado, ele deve ser construído. Essa pertença, esse vínculo com a cidade que está posta como modelo não existe, o que e existe é a cidade como uma paisagem, um cenário que lá está, wallpaper da lida, do percurso cansativo de ida/retorno, do cotidiano que se coloca com certa rigidez frente a transformação. Mas há sim, uma conexão com uma cidade que se deseja construir, como nos mostrou os sujeitos desta pesquisa. Pensemos nisso: as discrepâncias econômicas e sociais moldam a todo tempo a nossa vida e nossas relações, e também, repercutem assim, deveras, na constituição da concepção e mundo dos sujeitos (aqui colocados como os jovens) e na intencionalidade com que os mesmos responderão ao mundo.

Outrossim, entendo que a baioneta que empurra o jovem para a ponta da prancha, é a mesma que o espera em seu despencar para atravessá-lo: a sociedade desigual que cobra não dá um retorno esperançoso quanto ao futuro. Teremos que construí-lo! As resistências cotidianas que passam desapercebidas, são escritas a dura pena na história, de modo sofrido, por grupos de jovens que se insurgem, que não querem sucumbir perante o que está posto e prescrito. Há um auspício que quer limitar as juventudes ao desemprego/subemprego, ao flagelo da violência, da cultura extremamente hedonista e consumista. Esse auspício se materializou e ceifa a cada hora possibilidades de transformação, ao mesmo tempo e que a própria vida se tornou desespero.

A cidade, como palco contemporâneo do tombamento da humanidade, e por vezes, por possuir sujeitos que nasceram sob o signo da teimosia, é palco da luta, do enfrentamento e do esperançar (que compreende que esperança não é esperar!):

As cidades se apresentam como territórios privilegiados de ação social da juventude. Os jovens fazem a cada dia uma nova cidade que, em grande medida, é terra estrangeira para aqueles que não compartilham dos mesmos referenciais de identidade e se tornam impotentes para reconhecer a multiplicidade de sinais que emanam de suas múltiplas práticas. A experiência social contemporânea fez da identidade juvenil algo profundamente associado ao hedonismo e ao sentido do lúdico das práticas de lazer, seja na forma do consumo individual do tempo livre ou ainda nas práticas em que o sentimento de pertencimento a um grupo dá a tônica dos relacionamentos. (CARRANO, 2003, p.109).

Nesse trecho Carrano (2003), nos elucida sobre um aspecto sobremaneira importantíssimo, e no mínimo, alarmante: os jovens reinventam a cidade! Mas como fazem isso, se quase tudo que está "montado" está contra eles? Talvez essa seja a força motriz da indignação e da necessidade de construir possibilidades, para que essa "ação social" seja mais 
contundente. Cabe aqui refletir, na contramão, a cidade como cidade-turística somente, que muitas vezes está colocada, ou está legitimada assim (e na maioria das vezes, uma cidade que não existe, é somente idealizada, em algum postal). A cidade, segundo o que os sujeitos entrevistados para essa pesquisa apontaram e foi demonstrado, está muito articulada através de seus "pontos de encontro", ou seja, espaços que possibilitam uma organização, uma socialização de suas vidas, e que a partir daí, constroem as suas identidades, mas levando consigo sim, aquilo que são, acreditam, representam e que também querem construir/formar.

Esses "pontos de encontro" desafiam de certa forma uma ideia pré-concebida de espaços fabricados para o consumo das juventudes, numa espécie de encaixe com uma cultura global que tenta produzir homogeneidades, que molda um ser, padroniza identidades e até mesmo subjetividades. Nesses espaços, as jovens que aqui estão presentes com as suas falas com base em suas vivências, nos demonstram esse desenvolvimento:

Faz tempo já, eu conheci ela e eu vi que ela ...eu nem conhecia, nem falava com ela, mas ela estava lá no Cruz, e ela falando que era vegana, e eu fiquei com isso, o que será que é vegano né? E eu fiquei bá, tá, fiquei com aquilo na cabeça e fui pesquisar na internet...tá descobri o que era que não consumia produtos de origem animal ... (Carol)

Nesse ponto, percebemos que uma das ex-educanda do Paidéia, Carol Constantino, que é sujeito desta pesquisa, afirma que determinados espaços da cidade como o Cruz, mercado de conveniências localizado no centro da cidade que se transformou em espaço de socialização de várias pessoas da cidade inclusive das juventudes, destacam-se como plataforma de um convívio, e para, além disso, para que se entre em contato com outras experiências, vividas e sofridas por outros sujeitos.

Entendo a partir desse trecho e de outros, que a há na cidade a possibilidade do estabelecimento de resistências, sejam elas de cunho cultural, político, social, espiritual e etc. A intencionalidade da vida desses sujeitos é potente demais, por mais que ao ficar no micro espaço, e que fique na esfera da invisibilidade, não venham à tona as vezes.

Essas atividades e esses encontros na cidade se baseiam principalmente no desvio, na ruptura. Na tentativa de recriar algo, um espaço que seja seu, um espaço que seja de seu grupo, ou que alcance o maior número de pessoas possível, as juventudes na cidade, tentam dar a sua "cara". O Cruz é um espaço na cidade que pode ser colocado como uma "zona neutra", ou seja, para além do ponto de encontro de vários "tribos" e grupos que possuem culturas diversas, várias juventudes (na diversidade socioeconômica) se encontram, ao mesmo tempo que, ficam "cada um na sua". Porém, nesses "pontos de encontro", como afirmou a 
Carol anteriormente, na concentração (de vários grupos) e na socialização (naquilo que é possível) entre vários sujeitos é onde se destaca as aprendizagens na/da cidade, como nos afirma o Rafa:

...tipo aqui a Praça Saraiva, a Praça Xavier, são tipo, pontos de encontro, o Cruz tá ligado, que que há anos é bem conhecido, bem badalado da cidade (...)É, exatamente é onde se encontra várias tribos, acho que é isso que te ensina, tá ligado? (Rafa)

A consolidação desses espaços passa por importante afirmação de grupos que passam a frequentar esses lugares, na maioria das vezes, a necessidade de deslocamento, que com certeza se faz com maior dificuldade com grupos que para se afirmarem ou cumprem o deslocamento ou a permanência no centro da cidade, após as suas jornadas de trabalho. Cabe então apontar, que esses espaços são construídos, e legitimados por vários grupos, e esses mesmos espaços acabam se tornando espaços de ocupação, em uma cidade que não é preparada, e no caso da cidade capitalista nem poderia, para receber a construção ou a potencialização de identidades, subjetividades e outros projetos que demandam projeções utópicas e que desafiem a realidade. Até mesmo nos espaços democráticos, ou nas cidades que se dizem possuir espaços democráticos, é extremamente difícil isso acontecer. É difícil que apareçam esses protagonismos que possam dar conta dessas subjetividades juvenis, ou que possam construir outras formas de cultura. Contudo, esses espaços e atividades que contestam na/a cidade, se fazem na quebra de um cotidiano. Ou na reinvenção de um outro:

Contudo as rotas do quotidiano não são necessariamente de passividade ou de rotina. As rotinas cruzam-se com as rupturas. As raízes etimológicas da palavra rotina apontam para um campo semântico associado à ideia de rota (caminho), do latim via rupta, de onde também deriva a ruptura. Isto é, a interrupção, o corte, o rompimento, a fractura, o desvio. Para muitos jovens, as rotas do quotidiano são, muitas vezes, rotas de ruptura, rotas de desvios múltiplos. E são nestas rotas que emergem os valores juvenis mais contestatórios. (PAIS, 2001, p.66).

Pais, aqui, trazendo essa ideia de rompimento ao sublinhar a ruptura/fratura de um cotidiano que está posto, afirma ainda mais a capacidade e a necessidade de se fazer e de se recriar "interrupções" na cidade. Dessas interrupções, as juventudes emergem sim, mas nada foi "dado" tudo foi através de uma determinada luta e resistência.

A constituição de espaços públicos que potencializem a identidade juvenil, numa perspectiva de pluralidade cultural, é uma aposta para a organização democrática das cidades. A experiência que elabora e reconhece a definição de limites internos e externos da corporicidade juvenil ocorre na tensão relacional entre os diferentes interesses individuais e coletivos. Os espaços de encontro na cidade podem demonstrar a incapacidade da onipotência e a verificação da existência da alteridade como a única via possível da construção da identidade e da convivência democrática. Analisando as práticas da cidade podemos contribuir para caracterizar 
os diferentes âmbitos da experiência da juventude, suas amplitudes, limitações e desafios socioculturais. (CARRANO, 2003, p. 119-120).

Nesse sentido Carrano também nos ajuda a pensar sobre esses espaços na cidade, aonde a própria juventude vem construindo seus protagonismos. Arrisco a afirmar que os espaços aonde a juventude pode ser quem quer ser, tem e deve ser construído. Certamente que o espaço onde as juventudes consigam desenvolver as suas identidades, e da mesma forma a sociedade de um modo geral, só será possível quando houver a derrubada dessa sociedade pautada pelo capital e o surgimento de uma outra, emancipada e humanizada na perspectiva de Marx e Freire, como já vem sendo apontado aqui nesse trabalho. Enquanto isso, a resistência nos espaços da cidade, que se dá pela articulação de sujeitos que se envolvem na aprendizagem que fazem coletivamente a partir de suas sobrevivências e experiências, é o que vem sendo apontado como possibilidade de transformação já agora, nesse estado de coisas.

A cidade por si só, não representa mais a "liberdade" ou "socialização", mas pelo contrário, tem sido e se aprofunda mais em diversas mazelas, fruto da exploração, das desigualdades socioeconômicas, base dessas cidades pós globalização, ou como diria Lefebvre, dessa sociedade urbana. Harvey acrescenta alguns elementos importantíssimos sobre isso:

\begin{abstract}
$\mathrm{O}$ ar da cidade liberta, afirmou-se um dia. Essa idéia tomou forma à medida que os servos escapavam dos grilhões que os atavam a fim de reivindicar liberdade pessoais e políticas no âmbito das entidades legais autogeridas das cidades medievais. A associação entre avida cotidiana e as liberdades pessoais, incluindo a de explorar, inventar, criar e definir novos modos de vida, tem uma longa e intricada história. Gerações de migrantes têm buscado a cidade como um porto seguro contra repressões rurais. No âmbito dessa formulação, se entrelaçam perfeitamente "cidade" e cidadão". Mas a cidade é também lugar de ansiedade e de anomia. É o lugar do estranho anônimo, da subclasse (ou, como preferiam nossos predecessores, das "classes perigosas"), espaço de uma incompreensível "alteridade" (imigrantes, gays, pessoas mentalmente perturbadas, pessoas diferentes em termos culturais, aos que trazem uma dada marca racial), o terreno da poluição (tanto física como moral) e de terríveis corrupções, o lugar dos condenados que precisam ser encerrados e controlados, o que torna a "cidade" e "cidadão" politicamente opostos na imaginação pública na medida mesma da sua ligação etimológica. (HARVEY,2004, p. 208-209).
\end{abstract}

É aqui então que se encontra também o ponto nevrálgico das discrepâncias e do principal motivo do porquê que a cidade deve ser transformada, pela sociedade, e também pelos jovens. É importante refletir de que David Harvey está falando sim de sua realidade, que é norte-americana e também por vezes discorre sobre aspectos das cidades europeias, porém, é importante perceber o quanto o padrão de desigualdade e de marginalização dos cidadãos está globalizado, da mesma forma, podemos analisar com base em nossas cidades, o 
número de pessoas que estão fora, deslocadas e isoladas dos espaços urbanos, seja pela perspectiva urbana e arquitetônica, seja pela incapacidade de participar de espaços de poder e decisões, aonde o verdadeiro sentido do público e da democracia deveria ser construído.

As cidades quase que são impensadas para a maior parte das mulheres e homens que nela vivem, e num fluxo constante de mercadorias e produtos, a própria humanização da cidade é nula. Confunde-se lazer com dinheiro, realização com consumo, e nessa "locomotiva descarrilhada", as relações humanas, e nesse caso a juvenil, está estraçalhada em meio a tantas necrofilias ${ }^{3}$ impostas pelo capitalismo nas cidades. Mesmo assim, entendo que as pessoas ainda são o mais importante da cidade, como a Anne nos demonstra, por mais que as cidades, por vezes, sejam pensadas e planejadas negando a humanidade:

(...)eu acho só que cidade é a gente que faz a cidade, as pessoas que fazem a cidade, então ela se ela é ruim é porque nós fizemos ela ficar ruim, ou boa (...) Eu acho que são as pessoas né? Cidade são as pessoas (...) (Anne)

Anne é um dos sujeitos dessa pesquisa extremamente importante, tanto para entender as relações da cidade, quanto às outras categorias dessa pesquisa. E nessa relação com a cidade, mesmo que a mesma tenha afirmado que estava "mais inserida mais na questão família", nos alerta que a cidade são as pessoas, e que ao mesmo tempo, há uma responsabilidade coletiva nos resultados e consequências que estão prontos ou que aparecerão em breve. Com certeza que há limitações na atuação social, e que para termos efeitos mais contundentes a partir da atuação das pessoas, o processo é lento. Porém, passa por nossas mãos e mentes, a construção da cidade que queremos. Anne ao afirmar "nós fizemos ela ficar ruim, ou boa", não projeta a culpa para as pessoas de Rio Grande, mas chama para a transformação, para a participação, que passa por um abandono do cinismo e da famigerada culpabilização somente das entidades, instituições e organizações. Nesse sentido, entendo que as juventudes, trazem de suas vivências e reflexões, aprendizados que são profundamente imprescindíveis para construção de rupturas que possibilitem a construção de uma outra cidade. Da mesma maneira que constroem esses aprendizados na cidade, pois para além dos desafios cotidianos, a cidade propõe uma certa “educação", por vezes dura, por vezes insuficiente, mas é reflexo do que é a nossa sociedade:

\footnotetext{
${ }^{3}$ Faço uso do termo binômio biofilia-necrofilia da práxis freiriana, que significa mais uma ferramenta da cultura opressora de destruir, controlar, apropriar, explorar várias dimensões da existência humana. Segundo Zitkoski (2010), necrofilia em Paulo Freire seria "a tendência dos opressores de controlar tudo e todos", e também o fazer dos seres humanos "meras coisas, objetos do sadismo, o que caracteriza um impulso para a morte".
} 
Cara... cara a cidade pra mim é como se fosse uma escola. Ela te ensina muitas coisas. Ela te ensina aonde tu deve ir, como tu deve ir e como tu deve te comportar em determinados lugares, ta ligado? (Rafa)

E segue, principalmente na diferenciação entre os espaços da cidade e seus determinados comportamentos:

\begin{abstract}
Porque no bairro tu não poder ser..tu não pode ser muito educado no bairro. Tipo tu tem que cumprimentar todo mundo, se dar com todo mundo, sociabilizar com todo mundo sabe? Mas eu acho que ...se tu for muito educadinho, for isso e aquilo, tu vira...não chacota (...). E fora do bairro eu tinha que ter uma visão totalmente diferente tá ligado? Então tipo... cara cidade me educou muito tá ligado? Me mostrou como eu devo me comportar em determinado locais e a cidade é isso, eu acho que a cidade é um grande centro educacional. Tá ligado? (Rafa)
\end{abstract}

Percebemos aqui, a diferença social e cultural que existe dentro da cidade. Na minha perspectiva, o ethos do bairro Getúlio Vargas é diferente do ethos do cento da cidade, e por isso, há uma elaboração fendida na concepção de cidade, fruto das desigualdades socioeconômicas, e a necessidade de habituação a essas diferenciações de comportamento. Mesmo aqui, nessa sintetização que o Rafa faz das formas de socialização na cidade, e a própria sensibilidade de distinguir um espaço do outro, compreendo que essa divisão de comportamentos instaura uma maior dificuldade de propor as transformações da/na cidade, mas que não inviabiliza as resistências, as transformações, as aprendizagens e etc. Há uma cobrança profunda sobre os sujeitos, uma exigência que é típica da própria contemporaneidade:

A vida social nas cidades indica para os sujeitos a experimentação de identidades que colocam em jogo as múltiplas personalidades requeridas pelas relações sociais. A ideia de indivíduo portador de uma essência pessoal, a sua personalidade, que comporta no máximo, pequenos ajustes, segundo as relações estabelecidas, não dá conta da dinâmica da complexidade social. (CARRANO, 2003, p.120).

A desigualdade é sim o ponto central, a problemática maior, porém, nessas cobranças sobre os sujeitos, podemos entender que é uma ferramenta da segregação social. O aprendizado na cidade, não é algo somente positivo, ou seja, as pedagogias da cidade têm inúmeras metodologias para ensinar: falo do racismo, do preconceito, o isolamento e de outras segregações que impõe o padrão, que impõe hierarquicamente a homogeneização seja a sujeitos seja a grupos:

No espaço público da cidade contemporânea, o "capital escolar " e os modos de consumo são os elementos determinantes das identidades sociais. Aqui, diferença e 
desigualdade articulam-se no processo de apropriação espacial, definindo uma acessibilidade que é sobretudo, simbólica. Visto assim, acessibilidade a alteridade têm uma dimensão de classe evidente, que atua na territorialização (e, na maior parte dos casos, na privatização) dos espaços públicos urbanos. O conceito de habitus é sem dúvida a melhor ferramenta disponível para perceber como a dimensão de classe age sobre cada indivíduo na esfera cultural. A identidade social se define e se afirma a partir de uma alteridade que expressa também uma dimensão de classe, uma alteridade ao mesmo tempo "desigual" e "diferente". Desse modo, a acessibilidade ao espaço público da/na cidade contemporânea é, em última instância, "hierárquica". (SERPA, 2007, p. 20).

\title{
E é importante considerarmos essa perspectiva mais bourdiena com o que Harvey
} afirma também, no que tange a reconstrução do espaço urbano:

\begin{abstract}
Não obstante, também não podemos fugir à questão da imaginação, pois, como observou Marx (ed. 1976, p.283-284) - numa afirmação fundadora que adiante vamos examinar com bem mais profundidade -, o que distingue o trabalho humano $\mathrm{e}$ o pior dos arquitetos da melhor abelha é que o arquiteto primeiro erigem uma estrutura na imaginação para depois realiza-la em termos materiais. Quando, portanto, contemplamos futuros urbanos, temos sempre de combater uma ampla gama de sentidos emotivos e simbólicos que tanto informam como confundem nosso sentido do "caráter de [nossa] tarefa". Ao produzirmos coletivamente nossas cidades, produzimos coletivamente nossas cidades, produzimos coletivamente a nós mesmos. Projetos referentes ao que desejamos que sejam nossas cidades são em consequência projetos referentes a possibilidades humanas, a quem queremos ou, o que talvez seja mais pertinente, a quem queremos ou, o que talvez seja mais pertinente, a quem não queremos vir a ser. Cada um de nós, sem exceção, tem algo a pensar, a dizer e a fazer no tocante a isso. A maneira como nossa imaginação individual e coletiva funciona é, portanto crucial para definir o trabalho da urbanização. A reflexão crítica sobre nosso imaginário envolve, todavia tanto enfrentar o utopismo oculto como ressuscitá-lo a fim de agir como arquitetos de nosso próprio destino em vez de como "impotentes marionetes" dos mundos institucionais e imaginativos que habitamos. Se, como diz Unger (1987b, p.8), aceitamos que a "sociedade é construída e imaginada", podemos também crer que ela pode ser "reconstruída e reimaginada". (HARVEY, 2004, p.210-211).
\end{abstract}

A cidade pode e deve ser reconstruída, mas pelo processo de constatação de todas as dificuldades. Compreendendo o processo de desumanização que a sociedade atual sofre, tendo noção das limitações e desigualdades, e passando pelo processo de reimaginação, reconstruiremos esses espaços, ou em resistências faremos com que o os espaços que respiram contra hegemônica permitam maiores avanços ontológicos e epistemológicos para os sujeitos na/da cidade. Já que somos, falo da maior parte da cidade em si, retirados dos espaços de poder e decisão, negam-nos os direitos e cobram-nos os deveres de forma acintosa, os projetos de controle e subjugação são vários, temos que forçar a construção de uma cidade que seja democrática, no sentido radical da palavra.

Entendo que a reconstrução do espaço, seja a reconstrução de outras possibilidades e por isso, a reconstrução dos e das cidadãs, das pessoas, tanto no âmbito individual quanto coletivo. Entendo também, que a ocupação de determinados espaços pelas camadas populares 
é um projeto importante a se considerar, nessa perspectiva de ter "direito à cidade", como nos alertava Henri Lefebvre.

Mas como nos elucida Harvey através do pensamento marxiano, a retomada desta cidade, a retomada dos espaços ou a construção de espaços que consigam ser possibilidade do Ser Mais ou da Emancipação, passa antes pela imaginação, pela reflexão ou projeto desta transformação. A cidade (e a sociedade também) que queremos não passa por uma "arquitetura perfeita", mas antes disso, passará pelo crivo da construção de uma real democracia, ou como destaca Bensaïd (2010, p.87) a "verdadeira democracia", que é a emancipação.

O que me chama atenção principalmente nessa pesquisa, e é um dos elementos que analisei e que na minha perspectiva é extremamente potente, nesse viés de entender que a cidade não é somente "uma cidade", pois o próprio processo de urbano não é igualitário em sua formação, é o fato de que por mais que a periferia, ou os bairros que foram separados para as camadas populares da cidade, possuir uma resistência por parte dos sujeitos que lá vivem e sobrevivem.

Por mais que haja um sofrível processo de marginalização, criminalização e isolamento dos bairros afastados ou que não são centrais e comerciais na cidade, as populações desses bairros, compreendem-se sim como humanos dentro do processo de desumanização. Além da segregação, existe sim, uma força que chamo aqui de resistência ontológica e epistemológica, que possibilita os mesmos sujeitos a visualizar a sua condição frente a desigualdades e dificuldades e mesmo assim desenvolver a força capaz de enfrentar o modus operandis e por vezes superá-lo.

No próprio entendimento de inconclusão e de limitação frente a essas dificuldades, a percepção de que as suas vidas são importantes, e de que há possibilidade de transformação, potencializa certamente a legitimidade de seu bairro, do lugar aonde vive/mora, por mais que hegemonicamente já esteja colocado de modo vertical, quais são os bairros e zonas mais importantes da cidade.

Mesmo assim, trago em destaque algumas partes das falas dos sujeitos desta pesquisa, que foram elencadas e analisadas, e entendo que trazem muitos elementos que potencializam as discussões aqui propostas. Nesse momento uma das mais pulsantes, é a força do pertencimento do e com bairro e de seu habitus, da construção social que lá existe, baseado na

\footnotetext{
${ }^{4}$ Daniel Bensaïd (1946-2010), filósofo francês marxista de tradição trotskista, ex-dirigente da IV Internacional Comunista, ex-docente da Universidade Paris VIII, desenvolve a concepção da emancipação humana no posfácio da obra Sobre a Questão Judaica, demonstrando como Marx pensava a mesma concepção na linha de uma "verdadeira democracia", resgatando o sentido radical do processo democrático.
} 
cultura do mesmo bairro e que de certa forma, enfrenta a cidade propriamente dita. Nessa perspectiva, o Rafa nos fala:

E aí eu vi que era muito isso, que o bairro era a cidade, principalmente quando tu é novo assim, e é bem isso, tá ligado, depois de um tempo a gente começou a sair do bairro, pra tipo ir a escola, ou outras coisas, aí a gente começou a ver que o mundo não era o bairro Getúlio Vargas... (Rafa)

As aprendizagens que a socialização no bairro traz, constroem esse primeiro arcabouço sociocultural, e que aos poucos vai te enriquecendo na perspectiva como cidadão. Certamente que, como foi apontado antes, a "educação" no bairro é diferente, e por mais que seja desconsiderada, apresenta algumas características que não são melhores ou piores, mas já construídas, dizem respeito e se encaixam mais com esses sujeitos desses bairros. É importante notar que o Rafa nos traz que o " bairro era a cidade", mas com o tempo se percebe e se constata que o "mundo não era o bairro Getúlio Vargas". Entendo com isso que de nenhuma forma, o bairro com suas dificuldades e outras questões próprias, "perde” para o centro ou outras zonas e bairros (Rafa afirma nas entrevistas que mesmo vivendo o seu bairro, possuía uma relação com o centro da cidade e no período noturno), mas pelo contrário, o "BGV"5 não deixa de ser importante.

Para além disso há o reconhecimento também de que por mais que haja essa importância seja real, é necessário se abrir para as vivências e aprendizados do mundo, com a vida e com as experiências seguintes.

Há por isso, a partir da importância que o bairro possui na vida das pessoas que lá vivem e principalmente da juventude, uma tentativa de levar um pouco do bairro consigo, para os outros bairros e para as outras pessoas, e a necessidade de afirmar que são do bairro:

E mesmo quando tinham outros espaços, a gente saia sempre em grupo, tá ligado, e acho que é pra gente querer levar um pouco do bairro com agente, porque tipo, eu ia pras baladas para os lugar mais público e os guris gritavam "uh é BGV! ”, porque é aquela necessidade de tu levar o bairro. (Rafa)

Entendo aqui, a presença de uma cidade dentro de outra cidade. A cidade que é o bairro, em oposição a cidade central, das zonas centrais, pulsa aqui! Se faz necessário "levar o bairro", por ser fator de constituição desses sujeitos, e principalmente, por ser fator formador

\footnotetext{
${ }^{5}$ BGV é o bairro Getúlio Vargas, zona periférica da cidade. Próxima a região do Porto Novo e da Refinaria. Na fala riograndina, mais conhecido como $\mathrm{BGV}$, e no senso comum conhecido como uma zona criminosa, por mais que o bairro apresente uma antítese no cotidiano, e tenha uma cena sociocultural ativa, assim como uma "vida" comunitária no que tange as associações comunitárias e etc.
} 
dessas subjetividades, é impensável ser diferente. Destaco a importância de demonstrar para a cidade em si, e os espaços em que se inserem, de onde veem, a que bairro pertencem e etc.

E aí eu acho que é isso cara, que muito de mim ainda acha que o bairro é minha casa ta ligado, que meu bairro é aonde, é o meu lugar aonde eu me sinto melhor. Mas eu aprendi a me adaptar a outros lugares porque, eu acho que a vida é muito longa e ao mesmo tempo curta, tá ligado, e tu tem que aprender muitas coisas e dentro do teu bairro, chega uma hora que é um limite, tu já aprendeu tudo que tinha para aprender naquele ambiente, aí tu tem que ir para o externo tanto levar o teu conhecimento quanto trazer de outros ...tem uma frase do Emicida que eu gosto pra caramba que diz assim ó "nunca volte para sua quebrada de mão e mente vazia “, tá ligado ? E é exatamente isso, a gente tem que levar conhecimento e trazer conhecimento. (Rafa)

A minha análise caminha na perspectiva de que o bairro, nesse momento sendo a cidade de alguns sujeitos, é preponderante na ideia de construção de conhecimentos, de cultura, de elementos que dão uma segurança na vida dos mesmos. Percebo também, a constatação de que por mais que entendendo que a sua "cidade" é capaz de dar uma base para a sua socialização, percebo também a sensibilidade de estar aberto aos "conhecimentos" ou as vivências em outros espaços. Da mesma forma que se leva a sua cultura para outros bairros e lugares na cidade, da mesma forma o aprendizado nos outros bairros e lugares é importantíssimo.

Nesse trecho de fala, uma hipótese que eu tinha se confirma: não há legitimidade cultural somente no monumento, na praça, na câmara de vereadores, na prefeitura, no teatro, no cinema, na galeria de arte, na universidade, no shopping ou nos pontos turísticos. A cultura, e a produção de conhecimento na cidade está para além desses espaços. E é importante potencializar a cultura, o conhecimento e a sabedoria que ficam invisíveis, ou por serem rotulados como ethos de um bairro pobre, negro, criminoso e vulgar, se estigmatiza a não cultura desses sujeitos que lá vivem.

Rafa ao fazer uso da frase do Emicida $^{6}$, se conecta ao rapper na emergente necessidade de legitimar a sua existência e a de seus pares, e da mesma forma, legitimar a importância da sua quebrada ${ }^{7}$.

\section{Considerações Finais}

É imprescindível para a construção de uma resistência na cidade, ou de uma cidade resistente, que os saberes, conhecimentos e outras culturas sejam estabelecidas, venham a emergir através dos sujeitos e de coletivos também. Para que se tenha "direito à cidade", será

\footnotetext{
${ }^{6}$ Nome artístico do rapper e produtor musical brasileiro Leandro Roque de Oliveira.

${ }^{7}$ Bairro, periferia ou vizinhança. Termo muito usado nas gírias e em letras de rap, funk e na literatura marginal.
} 
necessário tanto o desenvolver de outros espaços que consigam dar conta de uma noção de público diferente da que foi estabelecida pela sociedade urbana, daquilo que foi cristalizado pela democracia do capital. E da mesma forma, a ocupação de espaços na cidade que já existem, mas que são renegados para a maior parte da população, se fará pela transformação, pelo entendimento de que o público deve ser público radicalmente.

Para as juventudes que foram os sujeitos desta pesquisa, que são os jovens do Paidéia e da cidade de Rio Grande, foi ressaltado que a Educação Popular contribuiu e contribui para a disputa pela cidade, para o Direito à Cidade, que esses mesmos sujeitos já buscavam de alguma forma. Do mesmo modo, o Paidéia como projeto de educação popular transformadora e crítica, auxiliou reforçando junto com esses sujeitos que as suas experiências e suas resistências na cidade forame e ainda serão imprescindíveis na construção de um projeto emancipatório, político e transformador. Assim como o mesmo Paidéia se potencializava como educação popular na medida em que compreendia esses sujeitos e suas resistências como protagonistas.

\section{Referências}

BENSAÏD, Daniel. Posfácio: "Na e pela história." Reflexões acerca de Sobre a questão judaica. In: MARX, Karl. Sobre a Questão Judaica. São Paulo: Boitempo, 2010.

CARRANO, Paulo César Rodrigues. Juventudes e Cidades Educadoras. Petrópolis, Rio de Janeiro: Vozes, 2003.

FERREIRA, Samuel Crissandro Tavares. E Se a Cidade Fosse Nossa: a Educação Popular Contribui na Emancipação das Juventudes na Cidade? Dissertação (mestrado) Universidade Federal do Rio Grande - FURG, Programa de Pós-Graduação em Educação, Rio Grande/RS, 2018.

FREIRE, Paulo. Pedagogia do Oprimido. 60. ed. Rio de Janeiro: Paz e Terra, 2016.

HARVEY, David. Espaços de Esperança. São Paulo: Edições Loyola, 2004.

JARA, Oscar H.; FALKEMBACH, Elza Maria Fonseca. Educação Popular e Sistematização de Experiências. In: STRECK, Danilo R.; ESTEBAN, Maria Teresa (orgs). Educação Popular: lugar de construção social coletiva. Petrópolis, RJ: Vozes, 2013.

MEJÍA J., Marco Raúl. La Educación Popular: uma construcción colectiva desde el sur y desde abajo. In: STRECK, Danilo R.; ESTEBAN, Maria Teresa (Orgs.). Educação Popular: lugar de construção social e coletiva. Petrópolis, RJ: Vozes, 2013, p. 369-398.

PAIS. José Machado. Ganchos, Tachos e Biscates: jovens, trabalho e futuro. Porto: Ambar, 2001. 

V. 05, ed. especial, abr., 2019, artigo $n^{\circ} 1329$ | claec.org/relacult | e-ISSN: 2525-7870

SANTOS, Milton. O Espaço da cidadania e outras reflexões. Porto Alegre: Fundação Ulysses Guimarães, 2011.

SERPA, Angelo. O Espaço Público na Cidade Contemporânea. São Paulo: Contexto, 2007. 